\title{
LA SIMILITUD Y LA DIFERENCIA EN LOS ORÍGENES DE LA ESCOLARIZACIÓN FORMAL EN RAPA NUI Y LA POBLACIÓN FUEGUINA EN ISLA DAWSON: EN BUSCA DE LA CONSTRUCCIÓN DE UN HABITUS OCCIDENTAL
}

JAVIER CORVALÁN ${ }^{a}$

\section{RESUMEN}

El artículo analiza y compara los procesos de desarrollo del habitus occidental mediante prácticas educativo-evangelizadoras en Isla de Pascua (población rapanui) y en Isla Dawson (población alacalufe o kawésqar y ona o selḱnam). Se argumenta cómo en ambas situaciones y en épocas relativamente similares se intenta un proceso de transformación y reemplazo cultural mediante prácticas culturales que buscan ser totalizadoras y sistémicas. Se establece que las diferencias entre ambos casos obedecen a factores contextuales pero que son solo dos variaciones de un mismo proyecto occidental de transculturación.

PALABRAS CLAVE: fueguinos, rapanui, Isla Dawson, habitus, educación.

\section{SIMILARITY AND DIFFERENCE IN THE ORIGINS OF FORMAL SCHOOLING IN RAPA NUI AND THE FUEGIAN POPULATION IN DAWSON ISLAND: IN SEARCH OF THE CONSTRUCTION OF A WESTERN HABITUS}

\begin{abstract}
The article analyzes and compares the processes of development of the western habitus through educational-evangelizing practices on Easter Island (Rapanui population) and on Dawson Island Kawésqar (alacalufe) and Selk'nam (ona) populations. It is argued that in both situations and in relatively similar times a process of transformation and cultural replacement is attempted through cultural practices that seek to sum up and be systemic. It is established that the differences between both cases are due to contextual factors but that they are only two variations of the same western transculturation project.
\end{abstract}

KEY WORDS: fuegians, Rapanui people, Dawson Island, habitus, education. 


\section{INTRODUCCIÓN}

Tanto en Isla de Pascua como en el extremo sur de Chile se llevó a cabo en las últimas décadas del siglo XIX y para el caso de la región austral de Chile además en la primera del siglo $\mathrm{XX}$, un proceso educativo civilizatorio y occidentalizador, sobre población originaria, de acuerdo a los cánones de la época. Aun cuando hay diferencias entre ambos procesos, las similitudes nos parecen mayormente claras a la luz de algunas categorías conceptuales y por ello la hipótesis de trabajo de este artículo es que ambas experiencias dan cuenta de un proceso de construcción e intento de interiorización de un habitus occidental mediante la instrucción religiosa entremezclada con una forma rutinaria de escolarización. Para avanzar en esta hipótesis haremos el siguiente recorrido: en primer lugar, recapitularemos en el surgimiento del concepto de habitus en la teoría sociológica entendido específicamente dentro del proceso de anomia generado por la desestructuración cognitiva implícita en todo proceso de cambio social acelerado, para luego analizar la relación entre la educación formal de tipo religioso y tal concepto (habitus) mediante la interiorización cognitiva y colectiva de prácticas sociales. Tal explicación da cuenta de la unidad conceptual de tipo formal identificable entre los procesos evangelizadores y la práctica educativa regular, generando la primera un paso fluido a la segunda. En segundo lugar, expondremos las características que tuvo la acción misionera en Rapa Nui y en la isla Dawson, señalando sus similitudes y diferencias en cuanto a prácticas y en consecuencia en la instauración de habitus occidental, aplicando para ello los conceptos de la primera parte del artículo.

\section{UN COMIENZO DURKHEIMIANO}

Como otros analistas de la sociedad de su época Émile Durkheim, hacia fines del siglo XIX, constata una sociedad occidental en un profundo proceso de cambio interno. Durkheim observa el avance de la modernidad con su estela de secularización y de individuación, producto de nuevas y crecientes divisiones del trabajo, proceso que al igual que a otros pensadores de la época, le genera reflexiones contradictorias.
En efecto, por un lado, la sociedad europea $y$ sus derivados en el mundo, que no eran pocos gracias a su proceso de diáspora y expansión colonial desde el siglo XVI, consolidan un ideario paulatino de mayor libertad individual y colectiva. Por otro, la desacralización del mundo y su consiguiente auto-responsabilización individual sin tener a la mano un referente sobrenatural podían provocar lo que nuestro autor denominó anomia, la sensación de un mundo sin normas y por ello un proceso angustiante para los individuos:

Si la anomia es un mal, lo es, ante todo, porque la sociedad la sufre, no pudiendo prescindir, para vivir, de cohesión y regularidad (...) Para que la anomia termine es preciso, pues, que exista, que se forme un grupo en el cual pueda constituirse el sistema de reglas que por el momento falta (Durkheim, 2001, p. $6)$.

Durkheim desarrolla parte importante de su análisis en torno a dos fenómenos centrales de la sociedad occidental de fines del siglo XIX, uno de ellos amenazado por los cambios imperantes y el otro que emerge como la solución a tales amenazas: la religión y la educación, respectivamente, teniendo ambos en común el hecho de constituir procesos eficaces de socialización colectiva cohesionando a la sociedad en torno a referentes compartidos:

Más aún, es imposible encontrar en la historia una crisis tan grave como esta en la que están empeñadas las sociedades europeas desde hace más de un siglo. La disciplina colectiva en su forma tradicional ha perdido su autoridad como lo demuestran las tendencias divergentes que desgarran a la conciencia pública y el ansia general que de alli se deriva (Durkheim, 1976, p. 254).

Si para Durkheim tal proceso socializador común está de manifiesto en las prácticas religiosas y escolares, nuestro autor también observa y conceptualiza de manera extremadamente lúcida otro aspecto vinculante entre ambas: su forma. Con ello Durkheim señala algo que desde entonces, 
con mayor o menor fuerza, ha marcado los análisis religiosos y educativos en tales sociedades, nos referimos a la continuidad de prácticas rituales entre el cristianismo y la escolarización moderna. Así, indica Durkheim, la casi totalización cultural y social que realizó el cristianismo durante siglos sobre las sociedades occidentales, tanto a nivel de la esfera pública como privada, se expresó formalmente en su ritualidad central consistente en la misa y en sus prácticas aledañas cuya similitud posterior en la práctica escolar era evidente:

Lo que constituye la autoridad con la que se reviste tan fácilmente la palabra del sacerdote es la elevada idea que tiene de su propia misión, porque sabe que habla en nombre de un dios en el que se cree y al que él se siente más cerca que la masa de los profanos. El maestro laico puede y debe tener también algo de esta persuasión. También él es el mandatario de una gran persona moral que lo supera: la sociedad. Y lo mismo que el sacerdote es el intérprete de su dios, el maestro es el intérprete de las grandes ideas morales de su tiempo (Durkheim, 1976, p. 112).

La ritualidad religiosa cristiana, como otras prácticas recurrentes en tal ámbito y probablemente también como las de otras religiones, constituyó -y lo hace hasta la actualidad- una dialéctica permanente entre forma y contenido, entre significante y significado, entre interiorización cognitiva y conducta observable que hace que tales prácticas sean transportables, precisamente en tanto forma, significante e interiorización situada en un contexto específico a otros contextos, amoldándose a éstos con relativa facilidad y sin provocar mayor disonancia en la subjetividad de los individuos. Frente al problema de descohesión y anomia señalado por Durkheim, la educación masiva, pública y con rasgos comunes para todos los alumnos no solo parece ser un eficaz intento de solución sino también, un claro reemplazo de la forma religiosa por una forma laica. En efecto, la capilla pasa a ser la escuela, el maestro es el sacerdote, la sagrada escritura se convierte en libros de textos, la mancomunión de cristianos pasa a ser la de laicos de un Estado-nación, es decir, no de hermanos en la fe sino en la ciudadanía y en el derecho común. Los ciudadanos ya no son necesariamente hijos de Dios, sino de la patria y a partir de la escuela no están iluminados por la fe sino por el conocimiento occidental que encierra la buena nueva de la racionalidad científica. Pero la similitud no termina ahí, en estas formas, sino también en aquellas que se expresan a partir de las prácticas escolares: los alumnos se ponen de pie al entrar el maestro, uno de ellos lee y los otros guardan silencio y todos parecen estar rezando en sus pupitres al momento de un examen. Además, lo anterior sigue siendo un ejercicio de salvación, teniendo eso sí en cuenta que el proyecto es ahora salvar mentes y no almas.

El ritualismo cristiano tiene además un elemento común y central con la educación escolar: el disciplinamiento. Por tal, Durkheim entenderá un proceso que tiene «como objetivo la regularización de la conducta, implicando unos actos que se repiten cuando se repiten determinadas condiciones, pero que no procede sin autoridad. Es una autoridad regular» (1976, p. 195). Además,

\section{(...) La disciplina proporciona} hábitos a la voluntad, le impone frenos. Regula y contiene. Responde a todo lo que hay de regular, de permanente. (...) Dado que la vida social es siempre, en cierta medida, semejante a sí misma y puesto que las mismas circunstancias se combinan y se reproducen periódicamente, es natural que ciertas maneras de obrar, que se han revelado como más relacionadas con la naturaleza de las cosas, se repiten con esa misma periodicidad. Es la relativa regularidad de las diversas condiciones en que nos vemos situados la que implica la relativa regularidad de nuestra conducta (p. 209).

De lo anterior se entiende que para Durkheim existe una similitud entre socialización y disciplinamiento y que ambos son en gran medida una función de las prácticas religiosas y educativas. Precisamente prácticas como las desarrolladas en Pascua y Dawson a partir de la acción evangelizadora y educativa en un determinado momento nos permiten observar la conjunción y fuerte 
indiferenciación de ambos procesos. Así, frente a la pregunta de Durkheim respecto de cómo evitar el quiebre cognitivo y la anomia de los individuos en un mundo en creciente secularización y diferenciación social, la respuesta está en algo que ya ocurre sin que esté políticamente planificado: la continuidad de formas sociales, aun cuando su contenido cambie y al mismo tiempo su funcionalidad o al menos parte de ella, permanezca. Ella es en gran medida la función de la práctica religiosa:

Pues la función de las categorías es dominar y abrazar a todos los demás conceptos convirtiéndolos en los marcos permanentes de la vida intelectual. Pero para que puedan abarcar tal objeto, es necesario que se hayan formado a partir de una realidad de igual amplitud (Durkheim, 2014, p. 663).

Esta última línea de reflexión la desarrolla Durkheim en colaboración con su sobrino Marcel Mauss, quienes a comienzos del siglo XX abordan el tema de las clasificaciones sociales, sosteniendo que la experiencia de lo disperso e incoherente propio de procesos de diferenciación y disolución de antiguos lazos sociales, adquiere sentido mediante categorías estructurales provistas desde la sociedad hacia el individuo (Mauss \& Durkheim, 2017). Además, y aun cuando muchas veces no reconocida, nos parece que la lingüística saussuriana (Saussure, 1945) coexistente en el ambiente cultural europeo en el momento de las reflexiones mencionadas complementa lo anterior, en especial en lo que dice relación con las dicotomías de significante y significado y de lengua y habla. La primera dicotomía alude a la idea de relación entre forma y contenido, explicando de paso lo polisémico e incluso antinómico de algunos términos acústicamente similares en todo lenguaje. La segunda dicotomía -lengua y habla- nos comunica la idea de conservación y cambio lento de la estructura frente a la vitalidad y recreación permanente de la interacción lingüística. Así, la lengua protege al habla de la incomunicación creciente que la vitalidad del actuar lingüístico de los sujetos le inferiría a su propia comunicación: una forma estructurada mantiene la unidad en la diversidad del actuar cotidiano de los individuos.
Finalmente, una de las síntesis y aplicaciones más fecundas de parte importante de los enunciados anteriores es la que se encuentra en la teorización de Pierre Bourdieu, en especial en el concepto de habitus (Bourdieu, 1992, 2007), durante el último tercio del siglo XX. De origen aristotélico y recuperado para la antropología y sociología por Marcel Mauss (1971), el habitus será concebido por Bourdieu como una interiorización del mundo social experienciado, lo que ocurre fundamentalmente mediante la recurrencia de las prácticas formando dispositivos estructurales que entrelazan prácticas distintas. Así, señala originalmente Mauss:

Durante muchos años he repensado sobre esta idea de la naturaleza social del "habitus" y observen cómo lo digo en latín, ya que la palabra traduce mucho mejor que "costumbre», el "exis", lo "adquirido" y la "facultad" de Aristóteles (que era un psicólogo). La palabra no recoge los hábitos metafísicos, esa misteriosa "memoria», tema de grandes volúmenes o de cortas y famosas tesis. Estos "hábitos" varían no sólo con los individuos y sus imitaciones, sino sobre todo con las sociedades, la educación, las reglas de urbanidad y la moda (1979 p. 340).

Bourdieu será quien realice la aplicación de este concepto a elementos cercanos a las sociedades contemporáneas: la distinción y la aproximación de categorías mutuamente determinadas, siendo las clases sociales la más evidente de ellas. De esta manera, la posición de los individuos en el "espacio social" los aproxima y distancia de otros individuos y grupos en cuanto comparten o no el mismo habitus, el que se expresa no solo en abstracciones sino y sobre todo, en prácticas, que en tanto realidades dispersas adquieren unidad simbólica y cognitiva, generando pertenencia e identidad y requiriendo para tales efectos, de capitales diversos a los sujetos para permitirles primero decodificar y luego volver a codificar tales prácticas (formas) en conceptos englobadores (contenidos). Así entonces, el habitus permite reconocer prácticas sociales formalmente desconocidas, identificándolas ya sea como lejanas o cercanas 
y en este último caso, englobándolas dentro de una categorización o significante común. La sociología de la cultura y del poder que desarrolla Bourdieu a partir de la década de 1960 utilizará el concepto de habitus como un elemento central para comprender conductas y percepciones, es decir, práctica y cognición en tanto estructuración de sujetos al interior de espacios sociales definidos como campos simbólicos.

En definitiva, la casi totalización de lo social que realiza Bourdieu con el concepto de habitus permite comprender que la interiorización de esquemas perceptuales que son por definiciones generales y globales produce el ordenamiento sistemático de particularidades, es decir, lo aislado, distante $y$ diferenciado se relaciona social $e$ individualmente en cogniciones comunes, en otras palabras, diferentes prácticas son concebidas como parte de un mismo concepto o bien que un mismo concepto es aplicable a prácticas distintas. Tal capacidad unificadora de lo inicialmente disperso, producto de la incorporación de un determinado habitus, es la que produce, a la vez, distinciones, incluidas las jerarquizaciones simbólicas entre individuos y grupos.

A partir de estos referentes teóricos nuestro objetivo es ahora su utilización para comprender procesos de cambio cultural en sociedades tradicionales y no occidentales, en contacto con occidente. Se trata de un proceso de instalación de un nuevo habitus mediante la práctica religiosoeducativa y con ello de una preparación para el proceso de educación formal autonomizado a partir de una continuidad de forma entre la práctica religiosa y escolar.

\section{LOS CASOS EN ESTUDIO}

En 1864 desembarca en Isla de Pascua el sacerdote francés Eugène Eyraud de la congregación de los Sagrados Corazones (SSCC). Con algunos intervalos, Eyraud desarrolla ahí su acción evangelizadora hasta 1868, año en que fallece en la isla. Su obra fue continuada por otros sacerdotes de la misma congregación que se le habían unido y en 1871 uno de ellos escapa con parte importante de la población rapanui a Tahiti, huyendo de un conflicto con intereses occidentales ubicados en Pascua. Durante los siete años de trabajo evangelizador de esta congregación en la isla, la casi totalidad de la población es convertida al cristianismo mediante escuelas misionales ubicadas en dos sectores de ese territorio.

Por su parte en la isla Dawson, ubicada en el estrecho de Magallanes, misioneros italianos de la congregación salesiana llegan en 1889 con el propósito de fundar una misión, además de otra en Tierra del Fuego. El propósito de la misma era evangelizar, "civilizar" y proteger a indígenas kawésqar y selḱnam del entorno frente a la amenaza que constituía la expansión de los estancieros y la creciente presencia no regulada y amenazante de población occidental. Los misioneros, acompañados de las religiosas también salesianas de Hijas de María Auxiliadora, consiguen el arriendo de la isla Dawson por parte del gobierno chileno por un periodo de veinte años, en los cuales desarrollan la misión San Rafael Arcángel, pequeño complejo urbano por el que pasaron cientos de indígenas de ambas etnias e incluso algunos individuos del pueblo yagán. En ese periodo los salesianos y las religiosas llevan a cabo un proceso de evangelización y escolarización, incluyendo el trabajo productivo que fuese útil para mantener la misión y para el desenvolvimiento posterior de los indígenas en la economía occidental. Los misioneros dejan definitivamente la misión en 1911 llevando con ellos a un grupo de indígenas.

Es importante tener en cuenta un contexto político común en ambos territorios y que puede explicar la adhesión de parte de las poblaciones nativas a la acción misional, es decir, una "eficacia simbólica" de base política en el proceso transculturador emprendido. Se trata del encadenamiento de un proceso de agresiónprotección por parte de occidente, siendo en Pascua el francés Jean-Baptiste Onésime DutrouBornier el agresor, mientras que en Tierra del Fuego este rol está personificado principalmente por el rumano Julius Popper. En ambos casos se trata también de acciones genocidas en busca de espacio para la explotación ganadera occidental y mientras la población rapanui alcanzó a sobrevivir no sin dificultades, los selḱnam terminaron en un casi exterminio y los kawésqar fueron reducidos notablemente en número (Ver las semejanzas políticas del proceso en Foerster, 2012). 
EDUCACIÓN, CAMBIO SOCIAL, HABITUS Y PUEBLOS ORIGINARIOS

La educación occidental mediante la escuela -su instrumento privilegiado- ha sido, junto a la instrucción religiosa, uno de los procesos más eficaces para transculturar $e$ intentar asimilar a los pueblos ajenos a occidente. Este proceso tiene una dimensión colectiva -a nivel de reemplazo de sistemas de creencias y cosmovisiones- pero también una individual, que se refleja en la adquisición de gustos, aspiraciones y prácticas, que aunque distintos entre los individuos, pueden ser por ellos reconocidos como pertenecientes a un mismo esquema perceptivo. En América Latina ocurrió, además, una simbiosis socializadora entre religión y educación formal, ya que la mayor parte de las escuelas que inicialmente recibieron alumnos de pueblos originarios fueron de origen eclesial por lo que su acción educativa se entremezcló con el proceso de evangelización.

La transculturación que ha producido (no solo) la escuela y la religión en pueblos no occidentales, y en particular indígenas, es conceptualizable como la instalación -y con ello a su vez con una desinstalación- de un habitus. "Crear" un individuo occidental en alguien que no lo era o que no estaba destinado a serlo no es solo proveerlo o inducirlo a nuevas formas de vestir, hablar o pensar, sino a que ellas sean las únicas o las más legítimas para sí y que por lo mismo aspire a cultivarlas y que reconozca en otros que visten, hablan o piensan de manera parecida, a sus nuevos próximos, aun cuando físicamente puedan estar lejanos. Desarrollar un nuevo habitus en un individuo es desarrollar en él una nueva comunidad de referencia con las jerarquías y distinciones que ella tiene. La "instalación" de un habitus es un proceso lento y por ello posible solo mediante una práctica recurrente que se articule mediante formas, pero que también entregue -sin plena conciencia de ellas por parte de los individuos- un conjunto de contenidos (Lahire, 2005). La transculturación en tanto cambio de habitus se produce no solo con la enseñanza del uso de artefactos materiales y simbólicos sino también con la incorporación cognitivo-afectiva de ellos, es decir, con su apropiación como parte de prácticas sociales recurrentes que crean deseabilidad de aquéllos. No basta con que, por ejemplo, la población fueguina haya comenzado a usar vestimenta occidental sino también con que mediante la práctica recurrente la haya comenzado a interiorizar, es decir, que considere a tal vestimenta como la manera legitima de presentarse en el mundo y por lo tanto que la ubique jerárquicamente al mismo tiempo que disyuntivamente entre las maneras de vestir (occidental/indígena; moderna/antigua; deseable/ indeseable).

Un punto de inicio clave en este proceso de habitualización es el lenguaje que fue, además, distinto en su modalidad de imposición en Isla de Pascua y en Dawson. Los SSCC realizan su trabajo evangelizador aprovechando su experiencia en otras islas de la Polinesia y en particular en Tahiti y esto explica que tal labor se realice en lengua tahitiana, que por cierto era distinta a la lengua originaria de Rapa Nui (Corvalán, 2015). Esto significa que aun cuando en este trabajo transculturador no se impone una lengua occidental, de facto se le transmite otra lengua (y en otra lengua) a los nativos. El caso de los salesianos en Dawson es diferente, porque si bien es cierto en el mandato de los misioneros de esta orden estaba ser competentes en el mediano plazo en la lengua indígena de los evangelizados, los antecedentes indican que ello no fue así y que la lengua de transmisión hacia los fueguinos fue tanto el italiano como el español, pero no una lengua nativa:

A los indigenas onas y alacalufes no les imparten en la educación en su propia lengua. Les hacen aprender de memoria las oraciones y el catecismo en castellano. Debido a la premura que se les ha impuesto a los misioneros al venir directamente al lugar de la misión, son muchas las palabras italianas que a diario emplean y que los indios aprenden (Aliaga, 1984, p. 145).

Lo mismo es refrendado críticamente por Emperaire al señalar que los religiosos hablaban mal el español y que utilizaban siempre la lengua italiana entre ellos (...) Ninguno de los misioneros de Dawson aprendió jamás ni el ona ni el alacalufe (1963, p. 75). En consecuencia, es posible señalar que, más allá de su imposición, 
en ambos casos a nivel lingüístico se produce una diferenciación entre la lengua externa y aquella de la población nativa, estableciendo una distinción estructural -a partir del simbolismo que representa el uso lingüístico- entre su mundo y el exterior.

\section{SALVAJISMO Y CIVILIZACIÓN COMO LEGITIMACIÓN PARA EL CAMBIO DE HABITUS}

La transformación del habitus del otro y con ello la búsqueda de disolución del vínculo subjetividad-objetividad que constituye a los sujetos solo es políticamente viable en el marco de un proyecto de protección frente a la amenaza de ese otro o bien de su salvación evolutiva. En otras palabras, la legitimidad para transformar al otro en un no-otro (un próximo o un connacional) debe necesariamente basarse en una argumentación de déficit estructural pero subsanable en él.

Tal fue el caso de la acción misional en Pascua y Dawson puesto que acorde con la mentalidad de la época y con la entonces influyente teoría evolucionista cultural (Morgan, 1980), los religiosos instalados en ambas islas conceptualizan a los indígenas no solo como distintos a ellos y a la cultura occidental sino también como inferiormente diferentes, ubicados algunos peldaños más abajo en la escala evolutiva de las sociedades (Nicoletti, 2008). Esta idea de inferioridad conlleva una imagen de niñez cultural frente a una adultez occidental y a la vez en una percepción de peligro frente a eventuales reacciones inesperadas del "inferior". Respecto de los salesianos se señala que: (...) Don Bosco ${ }^{1}$, justificó con argumentos teológicos la insumisión natural de los indigenas, introduciendo un agente externo a sus fuerzas que no permitian que estos vieran la fe: el demonio (Nicoletti, 2008, p. 6). El concepto que engloba lo anterior es el de "salvajes" que en el caso específico de los rapanui se entiende como "canacas", término despectivo aplicado en esa época a los pueblos originarios de la Polinesia y corrientemente utilizado por Eyraud en las cartas enviadas a sus superiores. Estructuralmente esto obedece a la dualidad salvajismo-civilización como antípodas evolutivas.

1 Giovanni Melchiorre Bosco, fundador de la orden salesiana hacia mediados del siglo XIX en Italia.

2 Giuseppe Fagnano, máxima autoridad de la orden salesiana
Lo anterior queda claro en la carta que Monseñor Fagnano ${ }^{2}$ dirige al Presidente Balmaceda con el objeto de obtener la concesión de Dawson para efectos misionales: hace dos años doy misiones a los salvajes de la Tierra del Fuego, los que pobres y desnudos encontré, se entregarian de buena voluntad a la civilización (Fagnano en Kuzmanich, 1990, p. 49). Por su parte, Eyraud señala respecto de Pascua:

De este modo podré consagrar todo el día a la instrucción de los indígenas: es lo que he podido hacer desde mi llegada hasta mi partida (...) tanto muchachos como muchachas, han aprendido bastante bien las principales oraciones y misterios esenciales de la religión. Muchos han comenzado a deletrear y hay cinco o seis que leen regularmente. Estos resultados no parecerán brillantes; pero se deberá tener presente que estas pobres gentes no tenían la más leve idea de las cosas que debía enseñarle, que su lengua carecía de las palabras necesarias para designarlas, y que, cuando les enseñaba las oraciones, me era preciso aprender su lengua, lo que es más difícil de lo que se piensa. Con los salvajes no se pueden hacer preguntas ni pedir aclaraciones: os dicen el nombre del objeto que está delante de los ojos, pero no vayáis más lejos: no pidáis una definición: esto excede con mucho su inteligencia (...) (Edwards, 1918, pp. 30-32).

Por último, en Dawson observamos también que el apoyo político que recibe la misión salesiana de parte del senador conservador Abdón Cifuentes se basa en el reconocimiento de su trabajo civilizatorio: En sintesis, expone que el trabajo de la misión ha consistido en estos logros: enseñar a los indios normas de civilización tales como comer sentado, con servicios y andar vestidos (Aliaga, 1984, p. 43).

Para efectos de ilustrar algunas de las prácticas modificadoras de habitus nos centraremos comparativamente en cuatro de ellas,

en la parte sur de la Patagonia durante el periodo en que se desarrolló la misión de Isla Dawson. 
las que se desarrollaron de manera entremezclada: la transmisión de referentes de tipo universalista, el desarrollo de pautas de rutinización y de temporalidad, la vestimenta y espacialidad y la relación entre la evangelización y la forma escolar.

\section{UNIVERSALISMO RELIGIOSO VS PARTICULARISMO NACIONALISTA}

Un elemento común entre la labor llevada a cabo por Eyraud y los Sagrados Corazones en Isla de Pascua y los Hermanos Salesianos en Patagonia es la debilidad de un discurso nacional en sus procesos educativos y evangelizadores. Ello resulta mayormente explicable en el caso de Isla de Pascua ya que en tiempos de la evangelización referida este territorio no era parte de ningún Estado nacional, a diferencia del caso de los salesianos en Dawson que desarrollan su trabajo en un momento en que este territorio ya era parte de Chile. Incluso así, es importante considerar que aun cuando la Congregación de SSCC es de origen francés y que tanto Eyraud como otros evangelizadores que lo acompañan eran de esa nacionalidad, no existen registros de contenidos propiamente nacionalistas mediante su acción evangelizadora y educativa. En el caso de los salesianos la situación reviste otras especificidades ya que se trata de sacerdotes de origen italiano que como ya dijimos se comunicaban cotidianamente en ese idioma y que por ello y por realizar su acción en sectores argentinos y chilenos de la Patagonia -y probablemente también por otras razones- se consideraron algo distantes de esos respectivos Estados y gobiernos (Bascopé, 2011). Lo anterior explica que, en ambos casos, el contenido mayoritario de la enseñanza impartida tanto propiamente religiosa y más allá de ella sea occidentalizadoruniversalista y no particularista si por esto último se entiende a contenidos vinculados a una sociedad o Estado específico. Pese a esto, es importante considerar que en el momento en que se suceden los hechos y siguiendo a Laclau lo universal había encontrado su propio cuerpo, pero este era aún el cuerpo de una cierta particularidad, la cultura europea del siglo XIX (1996, p. 50).

3 Benedict Anderson grafica con elocuencia el universalismo de las comunidades religiosas: Pocas cosas son más impresionantes que el vasto territorio del islam que se extiende desde Marruecos hasta el archipiélago Sulú, el
En efecto, si bien el Estado-nación es una realidad de tipo universalista frente a la etnicidad (particularista), aquel es a su vez particularista frente a comunidades y referentes transnacionales, tales como la religión o la idea misma de civilización occidental, como bien lo plantea Hastings: con anterioridad a la llegada de una religión universalista con extensos textos sagrados, la experiencia y la formalización religiosa eran esencialmente étnicas y o locales (2000, p. 218).

Desde este punto de vista y a diferencia de otros procesos evangelizadores que identificaron la religión con comunidades nacionales, en Pascua y Dawson se produjo el cambio de referentes entre la etnia y un referente macro-universal, como es el cristianismo ${ }^{3}$. Lo que se buscó entonces fue prioritariamente el tránsito desde el "indio salvaje" al "indio-cristiano" sin pasar necesariamente (al menos en Dawson) por el "indio-chileno", proceso que en el caso específico de los selk'nam nunca llegó a producirse debido a su desaparición como sociedad.

En esta línea, es interesante la carta de Fagnano al Presidente Balmaceda que ya en parte citamos y en la cual el religioso da cuenta de su proyecto con una argumentación que no escapa a un sentido universalista proporcionado por la religión o por la educación:

El medio seguro de ganarlos a la civilización es proporcionarles trabajo al alcance de su inteligencia (...) abrigo la esperanza que en los veinte años se llegará a educar la nueva generación y los viejos se amoldarán poco a poco a las costumbres de nuestras (sic) civilización. No escapará a la alta penetración de V. E las grandes ventajas que les reportaría al territorio de Magallanes cuando todos los indios atraídos por la Ley del Evangelio y la comunidad de la vida comenzarán a vivir cristianamente, en lugar de ser hostiles a los cristianos, serán hombres útiles para el trabajo (Fagnano en Kuzmanich, 1990, p. 49).

de la cristiandad que va desde Paraguay hasta Japón, y del mundo budista desde Sri Lanka hasta la península coreana (Anderson, 2007, p. 30). 
Es importante señalar que también, en el caso de Dawson, esta falta de contenido nacionalista explícito del proceso en cuestión generó fuertes críticas a los salesianos por parte de sectores políticos chilenos en las cuales puede verse reflejada la polaridad nación-cristianismo como expresión, a su vez, de particularismo-universalismo:

El diputado Sr. Pleiteado, en su intervención... considera los salesianos como un verdadero peligro para las instituciones liberales del país (...) Son rebeldes, pues no han querido reconocer la soberanía nacional y pedir permiso para establecerse en el país. Son extranjeros que desconocen el Patronato chileno (Aliaga, 1984, p. 55).

Aliaga por su parte interpreta con claridad este argumento al señalar que en la disputa anterior:

Lo que está al fondo es la pugna de dos modelos que representaban las dos tendencias existentes a nivel nacional. Por un lado, se desea una "civilización" vinculada a la acción evangelizadora y unida a una dimensión de civilización en sentido antropológico cristiano. Para lograr esto, se plantea el establecer una misión exclusiva para los indios, bajo el control directo de los misioneros. Este modelo propiciado por los salesianos era, a su vez, respaldado por el Partido Conservador. Por el otro, se propicia un proyecto de estilo secular-laico conforme al cual, los indios deben ser integrados a la vida urbana, donde aprendan los hábitos de la vida civilizada y de la higiene. Este modelo es el que defienden los radicales $y$ libre pensadores. Es algo alternativo en que se sustituye el catecismo por el principio de la responsabilidad ciudadana y la adquisición de hábitos de trabajo. El amor a la patria juega un lugar importante hasta el punto que la misión católica debe ser un instrumento para que los indígenas se compenetren de los sentimientos patrióticos y se sometan a las leyes del país. No se declaran enemigos de que existan misiones católicas pero exigen que en su "campaña de evangelización" los misioneros realicen una tarea de civilización, esto es que formen ciudadanos útiles a la patria (pp. 61-62).

Como corolario de esta disputa un delegado del gobierno chileno

Sugiere que la escuela de la misión esté a cargo de un instructor chileno, a fin de que los indios puedan aprender el idioma patrio, ya que los sacerdotes italianos no tienen la preparación especial para enseñarlo. De este modo, sustituiría los actuales textos usados en las escuelas primarias del país por otros más adecuados a sus cortos alcances. Además, por ser chileno, los formará en el sentimiento nacional y en la idea de la patria (Aliaga, 1984, p. 90).

Aun cuando en Pascua como dijimos, la situación fue algo distinta ya que en el momento de la evangelización el territorio no estaba bajo dominio chileno, no deja de llamar la atención un argumento similar al anterior utilizado por funcionarios chilenos ya entrado el siglo XX:

luego de visitar la Isla, hizo presente la necesidad de atender a la educación de los pascuenses enviando profesores continentales que enseñaran el idioma patrio. Señaló, además, la falta de recursos materiales y de atención médica. En 1933, otro capitán de Navio, reitera lo planteado por uno de sus antecesores, señalando la necesidad del funcionamiento de una escuela pública con maestros (Cristino et al. 1984 , p. 58).

\section{RUTINIZACIÓN Y TEMPORALIDAD}

La interiorización de habitus mediante prácticas sociales requiere la reiteración de las mismas incluyendo una regularidad en su distribución temporal. Con ello, el habitus occidental y su interiorización deben ser comprendidos no solo a partir del contenido de las prácticas sino también 
en su ordenamiento temporalmente rutinario. Esto se observa en los dos territorios en análisis, por ejemplo:

En el informe del 3 de mayo de 1890 , Mons. Fagnano narra las costumbres de los indios y un poco la vida en la misión. Por las mañanas, salen temprano a buscar leña. Después de tomar desayuno, los hombres van a trabajar. Mientras realizan sus labores, el misionero aprovecha para que repitan, de tanto en tanto, la señal de la cruz y alguna palabra en español. Los niños, en cambio, iban a la escuela... Las mujeres, al momento de recibir el alimento, son invitadas a hacer la señal de la cruz (Aliaga, 1984, pp. 36-37).

Respecto de Pascua, Eyraud indica que

Tres veces al día la campana anunciaba las oraciones. Cuando estaban reunidos, recitaba la oración, que los asistentes repetian, palabra por palabra: era la oración propiamente dicha. Luego venía la clase, en que se repetían las oraciones, les enseñaba el catecismo, y aprendian a leer (Edwards, 1918, p. 31).

Además, la rutinización en Dawson se ve entremezclada con la instrucción diferenciada por género:

Lo propio era que las niñas de edad escolar fueran puestas bajo el cuidado de las religiosas... No poco trabajo les costó convencer a las indiecitas de que debian ajustarse a horarios, cortarse el cabello, perseguir a los parásitos, comer en platos, vestir decentemente, etc. (Massa, 1945, p. 330).

Como parte de esta rutinización socializadora una diferencia importante es la recurrencia a la práctica de "trabajo occidental" muy presente en Dawson y ausente en Pascua. Se trata de un proceso

4 Señala el mismo Fagnano: "Esperamos que estos serán los peones de las grandes haciendas que se establezcan en el territorio y así habremos cambiado a los enemigos de la civilización en factores y ayudantes del progreso interiorizador de la idea de "lo productivo" mediante el esfuerzo físico; un tipo de disciplinamiento con impacto observable en el entorno (producción económica) y que supone, por antinomia, la presencia del "trabajo no productivo" en la cultura originaria:

No se crea por esto que los indios se doblegan fácilmente al trabajo i que no requiera fatiga su educación e instrucción. Necesario es oir hablar a estos misioneros para conocer las dificultades con que tiene que luchar, en primer lugar para captarse la simpatía del indio, receloso por naturaleza i refractario a toda idea de sujeción a los cristianos, $i$ en segundo lugar, hacerlos cargos de las más sencillas normas de aseo y limpieza (Carta de M. José Fagnano Diario "El Chileno" No 3.537 Santiago 1 de enero de 1896, dirigida a Ramón Serrano M., en Kuzmanich, 1990, pp. 114-115).

Las consecuencias agregadas de esta práctica no son menores. No se trata solo de un proceso de socialización al trabajo, sino de la interiorización y encadenamiento de nuevos oficios y con ello de una nueva división social de éstos, de lo cual la instrucción entregada es producto y productora:

Al mismo tiempo que algunos misioneros se dedican a la instrucción intelectual de los pequeñuelos, otros se dedican a la instrucción manual de los indios mayores, enseñándoles los diferentes oficios e industrias que ya se han establecido en la isla, como ser: carpintero, ovejero, esquilador, lechero y quesero (Carta de M. José Fagnano Diario "El Chileno" N 3.537 Santiago 1 de enero de 1896, dirigida a Ramón Serrano M., en Kuzmanich, 1990, p. 114).

Lo anterior supone para los misioneros un efecto tanto subjetivo (autoestima del indígena frente al blanco) como objetivo (capacidad a futuro de incorporarse al mercado laboral $)^{4}$ :

del territorio" Carta de Monseñor Fagnano al ministro Ventura Blanco, 25-1-1894, en "Memoria del ministro de Relaciones Exteriores presentada al Congreso Nacional en 1895 ”, p. 50. 
Sin obligar a los indios, se les va induciendo a realizar distintos trabajos de modo que los naturales descubran sus habilidades y adquieran confianza en si mismos. De esta manera, no se sentirian inferiores al blanco y robustecerían su autoestima. Este método resultó muy positivo en el grupo de los "campañistas" o encargados de ir a buscar la carne para la misión. Debian ser diestros para cazar alguno de los vacunos errantes en la isla, lo cual creó un verdadero espíritu de superación entre ellos. Lo mismo puede decirse de los que trabajaban en la lechería y en la elaboración de la madera. En este aspecto se logró plenamente el objetivo de que los indigenas en la misión aprendieran un trabajo calificado que los capacitara como trabajadores útiles en esta región (Aliaga, 1984, p. 148).

\section{VESTIMENTA Y ESPACIALIDAD}

El tema de las prácticas de vestuario y de distribución espacial marca una diferencia, en los dos casos estudiados, respecto a procesos de transculturación. En relación a lo primero es necesario señalar que ambas poblaciones, en el momento de contacto con los misioneros, estaban escasamente vestidas para los criterios occidentales (en particular los kawésqar), lo que es relevado por los religiosos como un tema necesario a modificar en Dawson pero no en Pascua. Para los salesianos el proceso de vestir a los fueguinos a la usanza occidental es señalado como parte central de su estrategia educativa mientras que Eyraud no se refiere mayormente al tema. Los relatos respecto de Dawson señalan que la casi totalidad de los indígenas alli asentados llegaron a estar vestidos de manera occidental mientras que en el caso de Pascua ello ocurre solo hacia fines del siglo XIX, al parecer por motivos distintos a la instrucción religiosa.

Es importante reconocer estructuralmente a la práctica de la vestimenta (o a un estilo de ella) en sus diversas dimensiones. Por una parte, ella genera distinción entre los propios indígenas (aquellos ya asentados y vestidos y aquellos que no lo están); por otra, produce identidad formal (material) con occidente y en consecuencia con la "civilización". En tercer lugar, la vestimenta cubre no solo lo que hay que proteger sino también aquello que no debe ser visto, vehiculando nuevos conceptos de moral reflejada en partes del cuerpo. Por último, la vestimenta es una de las prácticas más cotidianas, recurrentes e intimistas que existen y con ello un eficaz método de (des)instalación de habitus. Como bien lo señaló Barthes hace algunas décadas: es entonces expresamente a nivel de la sociedad que la vestimenta debe describirse (...) la ropa es esencialmente un hecho de orden axiológico 5 (1957, p. 434).

Respecto de la espacialidad, las diferencias entre Dawson y Pascua también son notables y obedecen tanto a proyectos como a condiciones en que se llevó a cabo el proceso de evangelización. En efecto, en Dawson se trató de un conjunto de miembros de una congregación a quienes se les sumaron algunas religiosas mientras que en Pascua la presencia de misioneros es bastante más restringida en número. Esta realidad, probablemente junto a otros elementos, hizo que el proyecto de Dawson, a diferencia de Pascua, fuese una suerte de ciudadela:

Hacia fines de ese año 1894 , los informes ofrecen en detalle todas las construcciones que forman parte de la misión, esto es: la iglesia, la casa de misioneros, la casa de las Hijas de María Auxiliadora, las salas de clases, los talleres, el dormitorio de las niñas, el de los niños y de las viudas. Se pone un énfasis especial al señalar lo que últimamente se ha construido: hospital, panadería, matadero de animales, casas para los indios, cementerio y muelle (Aliaga, 1984, p. 49).

Se observa entonces cómo la misión en Dawson se desarrolló junto a un proceso no solo de asentamiento de indígenas tradicionalmente nómades sino también de urbanización.

En términos conceptuales respecto de este punto, Wacquant (2017) señala recientemente y parafraseando a Bourdieu y Sayad que: La aglomeración repentina a través de la reubicación forzosa gatilla una "transformación brutal y total" de "todos los niveles de realidad

\footnotetext{
5 Traducción propia.
} 
social" (p. 287). Las nuevas unidades de viviendas autónomas para familias individuales "acentúan $y$ aceleran el debilitamiento de los lazos de parentesco" y fomentan "el surgimiento de solidaridades basadas en la vecindad y sobre todo en la similitud de las condiciones de existencia" (Bourdieu \& Sayad, 1964, pp. 121). A este respecto Aliaga señala de Dawson que en 1894: Cada familia ocupa su casita, la que consta de una sola pieza. En el centro de esa habitación está el fuego que tienen siempre vivo (1984, pp. 51-52).

En Dawson, a diferencia de Pascua, el modelo de transculturación implantado es "reduccional", es decir, busca la concentración de la población indígena en un reducto urbanizado y separado de su hábitat original. Con ello el objetivo fue crear una etapa intermedia en el camino de los indígenas a la "civilización", una suerte de laboratorio en aislamiento en el que los indígenas fuesen culturalmente transformados antes de enviarlos a su nueva vida occidental. En consecuencia, tanto como a un modelo urbanístico, la experiencia de Dawson corresponde a un símil micro-estatal, cuyos funcionarios y autoridades son los sacerdotes y religiosas. Desde esta perspectiva, el proceso desarrollado se corresponde con lo que Bourdieu denomina una construcción estatal de las mentalidades (2007, p. 115) consistente en que en las sociedades diferenciadas, el estado está en condiciones de imponer y de inculcar de forma universal, a escala de un ámbito territorial determinado, unas estructuras cognitivas (, 2007, p. 116) ${ }^{6}$. En esta línea, Foucault propone el concepto de heterotopía, que parece muy adecuado para la Misión San Rafael en Dawson:

También existen, y esto probablemente en toda cultura, en toda civilización, lugares reales, lugares efectivos, lugares que están diseñados en la institución misma de la sociedad, que son especies de contra-emplazamientos, especies de utopías efectivamente realizadas en las

6 El mismo Lévi-Strauss hace ya varias décadas había aludido incluso al tratamiento conjunto de la dimensión espacial y temporal: es imposible concebir las relaciones sociales fuera de un medio común que les sirve como sistema de referencia (...) el espacio y el tiempo son los dos sistemas de referencia que permiten pensar las relaciones sociales cuales los emplazamientos reales, todos los otros emplazamientos reales que se pueden encontrar en el interior de la cultura están a la vez representados, cuestionados e invertidos, especies de lugares que están fuera de todos los lugares, aunque sean sin embargo efectivamente localizables ${ }^{7}$ (Foucault, 1984, p. 47).

Más específicamente entonces, la Misión San Rafael correspondería a una heterotopía de desviación: aquellas en las que se ubican los individuos cuyo comportamiento está desviado con respecto a la media o a la norma exigida ${ }^{8}$ (Foucault, 1984, p. 47).

\section{EVANGELIZACIÓN Y FORMA ESCOLAR}

En Pascua y en Dawson la práctica evangelizadora se entremezcla con la escolar a partir de una forma común, como ya lo hemos ilustrado. Ello constituye la expresión clara del postulado durkheimiano de transición entre una y otra mediante formas comunes en estado de fuerte indiferenciación, siendo la rutinización memorística su dispositivo común. En Dawson, por ejemplo, se realizó un proceso de educación musical que llegó a constituir una banda y que sintetiza la conjunción entre educación religiosa e instrucción escolar memorística: Los himnos a la virgen María, practicados en el espacio misional, pertenecían a la música católica italiana, de tradición escrita, que los nativos memorizaron vocal $e$ instrumentalmente. La música europea de tradición escrita no da lugar a improvisaciones, se imita (Fonseca, 2014, p. 37).

En ambos territorios se tiende a indiferenciar la evangelización o instrucción catequística con una proto-educación escolar ya que como vimos en las citaciones anteriores, se menciona el aprendizaje del Evangelio o de oraciones como parte de una dinámica de "clases", señalando que se aprende a leer mediante tales prácticas y que a los nuevos fieles se les denomina "alumnos" e incluso "profesor" al evangelizador.

(...) según su estructura particular, las sociedades humanas han concebido estas dimensiones de manera muy diferente (Lévi-Strauss, 1974, p. 344). Traducción propia.

7 Traducción propia.

8 Traducción propia. 
Así, las categorías escolares son permanentemente utilizadas en las cartas de Eyraud a sus superiores y al igual que en Dawson y que en la mayor parte de las escuelas de la época, la práctica educativa se lleva a cabo de manera diferenciada por género y el logro de ella está marcado por la palabra sintetizadora del éxito de la institución escolar: el aprendizaje.

\section{CONCLUSIONES}

Entender a los proyectos de transculturación como intento de cambio de habitus, más allá del éxito que hayan tenido, significa conceptualizarlos como prácticas sistémicas, es decir, cuyo resultado no busca efectos parciales sino totales. La totalidad de la vida individual y social a producto de la redefinición de la vinculación con una comunidad universal, las nuevas rutinizaciones, temporalidades, espacialidades, formas de vestir y formalización de las instancias de aprendizaje, apuntan a ello.

En la mayor parte de los autores socioestructuralistas -la perspectiva analítica que sustenta este artículo- esta noción sistémica está presente, señalando entre otros aspectos que un elemento de la realidad analizada no solo está en relación con los restantes, sino que existe como tal debido al tipo de relación con los otros. Es lo que Saussure señala en los orígenes de este pensamiento: una unidad (...) es un producto, una combinación de dos elementos solidarios, que sólo tiene valor por su acción recíproca en una unidad superior (1945, p. 152), que recoge Lévi-Strauss: en primer lugar, una estructura ofrece un carácter de sistema ${ }^{9}$ (LéviStrauss, 1974, p. 332) hasta Bourdieu: lo real es relacional (1994) y Foucault (1984):

El estructuralismo, o al menos lo que se agrupa bajo este nombre algo general, es el esfuerzo por establecer, entre elementos repartidos a través del tiempo, un conjunto de relaciones que los hace aparecer como yuxtapuestos, opuestos, implicados entre sí, en suma, que los hace aparecer como una especie de configuración ${ }^{10}$ (p. 46).

9 Traducción propia.
En tanto prácticas sistémicas, las analizadas en Dawson e Isla de Pascua refieren, para obtener significados, a opuestos conceptuales cuya base es la disyunción explícita salvaje/ civilizado siendo algunas de las restantes leer/ ignorancia, vestimenta/desnudez, trabajo/ ociosidad, protección/desprotección, cristianismo/ paganismo, entre otras. Observadas de manera sistémica estas dicotomías refieren -o deben referir- a configuraciones mayores articuladas en la conciencia y disposiciones de los sujetos mediante supra conceptos englobadores. Solo de esa manera hubiesen podido producir una eficacia simbólica y un nuevo habitus.

Lo ocurrido en Dawson y Pascua en tanto "laboratorios de transculturación" debe en definitiva ser observado como dos propuestas para un mismo proceso, cuyo análisis de eficacia y eventual resistencia agencial de sus poblaciones requiere sin embargo de nuevas investigaciones.

\section{AGRADECIMIENTOS}

Agradecimientos muy especiales a Marisol V.

\section{BIBLIOGRAFÍA}

Aliaga, F. (1984). La Misión en la isla Dawson (1889-1911). Santiago, Chile: Universidad Católica de Chile.

Anderson, B. (2007). Comunidades imaginadas. Reflexiones sobre el origen y la difusión del nacionalismo. Buenos Aires: Fondo de Cultura Económica.

Barthes R. (1957). Histoire et sociologie du Vêtement [Quelques observations méthodologiques] Annales. Économies, Sociétés, Civilisations, 36, 430-441.

Bascopé, J. (2011). Bajo tuición. Infancia y extinción en la historia de la colonización fueguina en Corpus. Archivos virtuales de la alteridad americana, 1(1), 1-16.

Bourdieu, P. (1992). Réponses. Paris: Seuil.

Bourdieu, P. (1994). Raisons pratiques. Sur la théorie de l'action. Paris: Seuil.

Bourdieu, P (2007). Razones prácticas. Sobre la teoría de la acción. Barcelona: Anagrama

Bourdieu, P \& Sayad, A. (1964). Le Déracinement. La crise de l'agriculture traditionnelle en Algérie. Paris: Minuit.

Corvalán, J. (2015). Educación en Rapa Nui. Sociedad y escolarización en Isla de Pascua. Santiago, Chile:

10 Traducción propia. 
Ediciones Alberto Hurtado.

Cristino, C., Recasens, A., Vargas, P., González, L., \& Edwards, E., (1984). Isla de Pascua. Procesos, efectos y alcances de la aculturación, Isla de Pascua: Instituto de Estudios Isla de Pascua-Universidad de Chile.

Durkheim, É. (1976). Educación como socialización. Salamanca: Sígueme.

Durkheim, É. (2001). La división del trabajo social. Madrid: Akal.

Durkheim, É. (2014). Las formas elementales de la vida religiosa. Madrid: Alianza Editorial.

Edwards, R. (1918). El apóstol de Isla de Pascua José Eugene Eyraud. Hermano de la Congregación de los Sagrados Corazones. Santiago: Imprenta Chile.

Emperaire, J. (1963). Los Nómades del Mar. Santiago, Chile: Ediciones de la Universidad de Chile.

Foerster, R. (2012). Isla de Pascua e Isla grande de Tierra del Fuego: semejanzas y diferencias en los vínculos de las compañías explotadoras y los "indígenas". Magallania, 40(1), 45-62.

Fonseca, N. (2014). "Servid al Señor con alegría", música en la misión San Rafael Arcángel (1889-1911). Magallania, 42(2), 23-39.

Foucault, M. (1984). Des espaces autres. Architecture, Mouvement, Continuité, (5), 46-49.

Hastings, A. (2000). La construcción de las nacionalidades. Cambridge; Cambridge University Press.
Kuzmanich, S. (1990). Presencia Salesiana 100 años en Chile. La expansión: 1888-1920. Santiago, Chile: Editorial Salesiana.

Laclau, E. (1996). Emancipación y diferencia. Buenos Aires: Ariel.

Lahire, B. (2005). El trabajo sociológico de Pierre Bourdieu. Buenos Aires: Siglo XXI.

Lévi-Strauss, C. (1974). Anthropologie Structurale. Paris: Plon.

Massa, L. (1945). Monografía de Magallanes. Sesenta años de acción salesiana en el sur 1886-1946. Punta Arenas, Chile: Escuela Tipográfica del Instituto Don Bosco.

Mauss, M. (1979). Sociología y Antropología. Madrid: Tecnos.

Mauss, M. \& Durkheim, É. (2017). Des quelques formes primitives de classification. Contribution à l'étude des représentations collective. Paris: Presses Universitaires de France.

Morgan, L. (1980). La Sociedad Primitiva. Bogotá: Editorial Ayuso-Editorial Pluma.

Nicoletti, M. (2008). El modelo reduccional salesiano en Tierra del Fuego: educar a los "infieles". Revista Tefros, 6(2), 1-18.

Saussure, F. (1945). Curso de Lingüística General. Buenos Aires: Losada.

Wacquant, L. (2017). Bourdieu viene a la ciudad: pertinencia, principios, aplicaciones. EURE, 43(129), 279-304. 